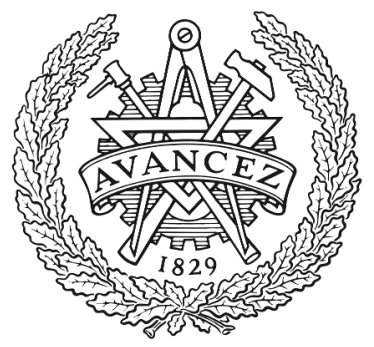

CHALMERS

UNIVERSITY OF TECHNOLOGY

\title{
Coating material-dependent differences in modelled lidar-measurable quantities for heavily coated soot particles
}

Downloaded from: https://research.chalmers.se, 2023-04-26 12:08 UTC

Citation for the original published paper (version of record):

Kanngiesser, F., Kahnert, M. (2019). Coating material-dependent differences in modelled lidar-measurable quantities for heavily

coated soot particles. Optics Express, 27(25): 36368-36387. http://dx.doi.org/10.1364/OE.27.036368

N.B. When citing this work, cite the original published paper. 


\title{
Coating material-dependent differences in modelled lidar-measurable quantities for heavily coated soot particles
}

\author{
Franz Kanngiesser, ${ }^{1,{ }^{*}}$ Michael Kahnert ${ }^{1,2}$ \\ ${ }^{1}$ Department of Space, Earth and Environment, Chalmers University of Technology, 41296 Gothenburg, \\ Sweden \\ ${ }^{2}$ Research Department, Swedish Meteorological and Hydrological Institute, Folkborgsvägen 17, 60176 \\ Norrköping, Sweden \\ *franz.kanngiesser@chalmers.se
}

\begin{abstract}
The optical properties of thickly coated soot particles are sensitive to the chemical composition, thus to the refractive index of the coating material. For 58 differently sized coated soot aggregates the extinction-to-backscatter ratio (lidar ratio) and the depolarisation ratio are computed at a wavelength of $355 \mathrm{~nm}, 532 \mathrm{~nm}$ and $1064 \mathrm{~nm}$ for two different coating materials: a toluene-based coating and a sulphate coating. Additionally the Ångström exponents between $355 \mathrm{~nm}$ and $532 \mathrm{~nm}$ as well as between $532 \mathrm{~nm}$ and $1064 \mathrm{~nm}$ are calculated. The extinction-to-backscatter ratio is found to allow a distinction between the coating materials at all three wavelengths, and the depolarisation ratio allows for a distinction at 355 and $532 \mathrm{~nm}$.
\end{abstract}

(C) 2021 Optical Society of America under the terms of the OSA Open Access Publishing Agreement

\section{Introduction}

Aerosol particles consisting of soot or light-absorbing carbon are, after carbon dioxide, among the most important individual warming agents in the Earth's climate system. Soot aerosol impact the climate by absorption of radiation, reducing the albedo of snow and ice in high latitude and high altitude regions, and they play a role in cloud formation processes [1-3]. Furthermore, soot containing particles have an adverse impact on air quality and human health [3,4].

Monitoring sources, transport paths and sinks of soot aerosol relies on the use of remote sensing techniques. With the help of such measurements it is possible to both constrain and improve aerosol transport models and air quality forecasts. The interpretation of data obtained with the help of remote sensing techniques requires a thorough understanding of the optical properties of aerosol particles.

Remote sensing applications use properties such as the linear depolarisation ratio $\delta_{l}$ and the extinction-to-backscatter ratio (or lidar ratio) $S_{p}$. Aerosol classification schemes used by the Cloud-Aerosol Lidar and Infrared Pathfinder Satellite Observation (CALIPSO) mission [5,6] and by Atmospheric Lidar (ATLID) instrument on board of the planned Earth Clouds, Aerosol and Radiation Explorer (EarthCARE) satellite [7] rely on $\delta_{l}$ and $S_{p}$. The depolarisation ratio is sensitive to the particle morphology [8,9] and even to particle inhomogeneities [10]. The extinction-to-backscatter ratio depends on the particle shape as well $[11,12]$.

Soot particles consist of strongly absorbing carbonaceous material, hence the term lightabsorbing carbon. Due to ageing processes in the atmosphere soot particles are frequently coated with weakly or non-absorbing material, which condenses onto the aggregates (e.g. $[13,14])$. In-situ measurements indicate that soot aerosol particles get rapidly coated, and that thickly coated soot particles are predominant [14-17].

The optical properties of such coated soot particles have been investigated using various optical models. Modelling differential optical properties, such as the depolarisation ratio, is often more complicated and requires more sophisticated models then the modelling of integrated optical 
properties, such as the optical cross sections [18]. Morphologically complex optical models of coated soot particles have been employed to investigate the linear backscattering depolarisation ratio [19-23]. The extinction-to-backscatter ratio of coated soot aerosol particles was modelled in [23]. There are further studies concerning the extinction-to-backscatter ratio of mineral dust aerosol particles such as $[11,12,24]$. The studies regarding the extinction-to-backscatter ratio of dust consider spheres, spheroids, and mixtures thereof.

With the help of four different models high values of the linear depolarisation ratio of soot containing aerosol were studied in [19]. One of the models consisted of a soot aggregate with each individual soot monomer of the aggregate embedded into a shell of coating material, the closed cell model. Another model consisted of a soot aggregate embedded in a spherical coating shell. The third model combined two spherical coating shells with smaller aggregates than in the previous model to a single model particle. The last model is a coated spheroid model.

An optical database for soot containing aerosol was presented in [22]. That database is based on eleven different models, of which three represent bare aggregates, two represent semi-external mixtures with soot monomers and a soot aggregate, respectively, attached to a sphere of coating material, another model represents soot aggregates partially embedded into a spherical coating shell, and the remaining models represent soot aggregates encapsulated in coating material. The models in [19], with the exception of the coated spheroid model, are among the five models for soot fully encapsulated in coating material described in [22]. The other two model particles are a core-shell model in which all soot is compacted into a sphere which is embedded in a spherical shell and a number of small individual spheres embedded into a spherical coating shell.

In [20] the closed cell model was compared with a coated aggregate model. The depolarisation ratios obtained with the two models are in good agreement for high soot volume fractions (or thin coatings) and deviate stronger for lower soot volume fractions. The coated aggregate model in [20] posed the risk of overestimating the depolarisation ratio. In [21] the coated aggregate model was further refined by taking the compaction of the aggregate with increasing coating thickness into account, and, most importantly, by introducing a tunable transition from film-coating following the aggregate shape to a spherical shell coating. It was demonstrated that this model is capable of covering a large range of depolarisation ratios by only tuning a single parameter; a faster transition to spherical shell coating yields lower values of the depolarisation ratio. This model will be employed in our study.

An artificial surface potential (analogous to microscopic surface potentials) mimicking the behaviour of water-soluble coating material is defined in [23]. The coating material is applied iteratively by applying the coating point by point from the highest to the lowest potential until a prescribed volume ratio of coating material to aggregate material is reached. With this particle model the linear depolarisation ratio and the extinction-to-backscatter ratio for various particle sizes and different coating thicknesses were calculated. Similar to the coated aggregate particles in [20], the model particles in [23] pose the risk of overestimating the depolarisation ratio.

As shown in [21] the linear backscattering depolarisation ratio of heavily coated soot particles is strongly sensitive to the complex refractive index of the coating material. Therefore we hypothesised that the coating material of an ensemble of thickly coated soot particles can be distinguished with the help of lidar-measurable quantities, such as the depolarisation ratio and the extinction-to-backscatter ratio. Here, we test this hypothesis by modelling optical properties of thickly coated soot particles, using the particle model described in [21]. With these model particles calculations for two types of coating material are performed at three different wavelengths, 355, 532, and $1064 \mathrm{~nm}$. 


\section{Methods}

\subsection{Particle model}

\subsubsection{Bare Aggregates}

Bare soot particles can be described as fractal aggregates consisting of $\mathrm{N}$ small spherical monomers of radius $a_{\text {mon }}$ following a scaling relation [25]:

$$
N=k_{0}\left(\frac{R_{g}}{a_{\mathrm{mon}}}\right)^{D_{f}}
$$

The fractal dimension $D_{f}$ describes how densely the aggregate is packed. Linearly aligned monomers would correspond to $D_{f}=1$ and a sphere would correspond to $D_{f}=3$. $k_{0}$ is called fractal prefactor and affects how densely monomers along a branch are packed [26]. The radius of gyration $R_{g}$ is defined as:

$$
R_{g}=\sqrt{\frac{1}{N} \sum_{i=1}^{N}\left|\vec{r}_{i}-\vec{r}_{c}\right|^{2}}
$$

Here $\vec{r}_{i}$ is the position vector of the $i$ th monomer and $\vec{r}_{c}$ is the position vector of the aggregate's center of mass.

Fractal aggregates were created using a cluster-cluster algorithm [27], which combines individual monomers and smaller aggregates to an aggregate with $N$ monomers with predefined values for $D_{f}$ and $k_{0}$. At each step of this process the aggregates follow the fractal scaling relation in Eq. (1). The resulting aggregates consist of monomers in point-contact. To describe overlap between neighbouring monomers we used the overlap factor $C_{\mathrm{ov}}$ as defined in [28] which is given as:

$$
C_{\mathrm{ov}}=\frac{d_{p}-d_{i j}}{d_{p}}
$$

The diameter of the monomer is given as $d_{p}=2 a_{\text {mon }}$ and $d_{i j}$ denotes the distance between two neighbouring monomers. If $C_{\mathrm{ov}}=0$ the two neighbouring monomers are in point-contact and if $C_{\mathrm{ov}}=1$ the monomers are completely overlapping. The previously created aggregates with monomers in point-contact are turned into aggregates with overlapping monomers by multiplying the coordinates of the monomers' respective centre with $\left(1-C_{\mathrm{ov}}\right)$ [29].

The number of monomers was increased from $N=26$ to $N=1508$ with equidistant steps of $\Delta N=26$. For each size five different stochastic realisations of aggregates with the prescribed fractal parameters have been generated.

The morphological properties used here were taken from field measurements [15, 17] and are shown in Table 1. Note that the overlap parameter $(\delta)$ used in [17] is defined as in [30], while here the overlap factor $C_{\mathrm{ov}}$ as defined in [28] was used. $\delta$ can be easily converted into $C_{\mathrm{ov}}$ by $1-\delta^{-1}=C_{\mathrm{ov}}$.

\subsubsection{Coated particles}

The coating material was added using the algorithm described in [21]. The algorithm is strongly connected to the use of the discrete dipole approximation (see section 2.2), i.e., the coating is added to the aggregate dipole by dipole. The coating follows the shape of the aggregate, but is constrained to lie within a sphere with a predefined critical diameter $D_{c}$. We chose to place the centre of the critical sphere in the aggregate's centre of mass (but different choices would be possible). Once the critical sphere is completely filled with coating material, the particle continues to grow radially, until a prescribed soot volume fraction is reached. (As in [20,21], the soot volume fraction is defined as the fraction of dipoles assigned to soot and the total number of dipoles in the coated aggregate.) The resulting model particles make a gradual transition 
Table 1: Morphological properties for the aggregates. Monomer radius, fractal prefactor and overlap factor are taken from [17], while the fractal dimension and the soot volume fraction are taken from [15].

\begin{tabular}{ll} 
property & value \\
\hline monomer radius $a_{\mathrm{mon}}$ & $28 \mathrm{~nm}$ \\
soot volume fraction $f_{\mathrm{vol}}$ & $7 \%$ \\
fractal dimension $D_{f}$ & 2.2 \\
fractal prefactor $k_{0}$ & 1.625 \\
overlap factor $C_{\mathrm{ov}}$ & 0.33
\end{tabular}

from film-coating to spherical encapsulation as more and more coating material is being added. The transition to spherical coating can be controlled by the free parameter $D_{c}$. The larger $D_{c}$, the "slower" the transition to spherical coating, i.e., the more coating material needs to be added before the coating is completely spherical. The idea behind this model is to tune the linear backscattering depolarisation ratio. Spherically coated particles depolarise weakly, while particles with nonspherical coatings depolarise more strongly.

The critical diameter $D_{c}$ of the sphere is expressed by the maximum dimension of the aggregate, $D_{\max }$, multiplied by a dimensionless factor $f_{c} \leq 1$, i.e., $D_{c}=f_{c} D_{\max }$. Based on the choice of $D_{c}$ in [21] and the relative difference in the onset of spherical growth for sulphate and organic coating as reported in [31] the critical diameter was set to $D_{\mathrm{c}, \text { org }}=0.6 D_{\max }$ and $D_{\mathrm{c}, \mathrm{SO} 4}=0.8 D_{\max }$. Differences in the shape of the coating between these two choices of $D_{c}$ only become apparent at intermediate and high soot volume fractions (i.e., intermediate and low amount of coating material). For the relatively low soot volume fraction considered here, the coating is spherical, both for toluene and for sulphate. Thus the difference between $D_{\mathrm{c}, \text { org }}$ and $D_{\mathrm{c}, \mathrm{SO} 4}$ do not cause any difference in the overall particle shape between both coating materials.

For the organic coating we assume the refractive indices reported for toluene-based secondary organic material from laboratory measurements in [32]. The refractive indices for sulphate were taken from the values used in the software package Optical Properties of Aerosols and Clouds (OPAC, version 3.2) [33]. The refractive indices for the soot aggregates were obtained with the help of the expressions reported in [34], which were derived by fitting measurements of soot aggregates (These measurements were limited to a wavelength range of $0.4 \leq \lambda \leq 30 \mu \mathrm{m}$; however the error introduced by extrapolating the expressions in [34] to $355 \mathrm{~nm}$ is relatively small [21].) The refractive indices for the different materials and wavelengths are listed in Table 2. While toluene-based coating is (mildly) absorbing at $\lambda=355 \mathrm{~nm}$ and $\lambda=532 \mathrm{~nm}$, sulphate is purely scattering, as can be seen from the imaginary part of the refractive index. At $\lambda=1064 \mathrm{~nm}$ sulphate is very weakly absorbing while the toluene-based coating becomes purely scattering.

Table 2: Spectral dependence of the complex refractive indices used for the different materials

\begin{tabular}{lllll} 
& $355 \mathrm{~nm}$ & $532 \mathrm{~nm}$ & $1064 \mathrm{~nm}$ & \\
\hline toluene & $1.5824+\mathrm{i} 0.0247$ & $1.5518+\mathrm{i} 0.0008$ & $1.5279+\mathrm{i} 10^{-8}$ & {$[35]$} \\
sulphate & $1.45+\mathrm{i} 10^{-8}$ & $1.43+\mathrm{i} 10^{-8}$ & $1.42+\mathrm{i} 1.53 \cdot 10^{-6}$ & {$[33]$} \\
soot & $1.6628+\mathrm{i} 0.7152$ & $1.7316+\mathrm{i} 0.6$ & $1.8189+\mathrm{i} 0.5905$ & {$[34]$}
\end{tabular}




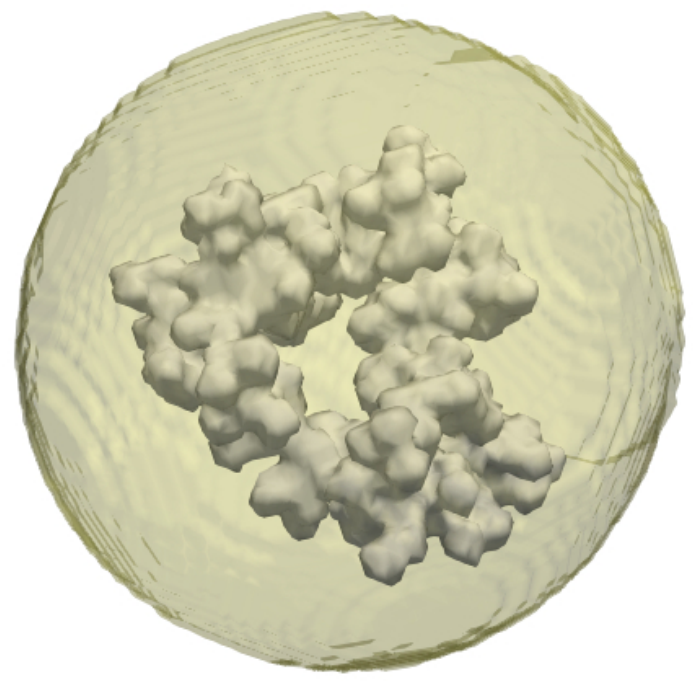

Fig. 1: Example of a coated soot aggregate consisting of $\mathrm{N}=286$ overlapping monomers as used in the calculations. The aggregate is shown in grey and the coating shell in yellow.

Figure 1 shows an example of a coated soot model particle as used in the calculations. The aggregate, consisting of 286 overlapping monomers with fractal parameters as given in Table 1, is shown in grey, and the coating is represented by the yellow color.

\subsection{Optical calculations}

The optical calculations are performed for the wavelengths of $\lambda=355 \mathrm{~nm}, \lambda=532 \mathrm{~nm}$ and $\lambda=1064 \mathrm{~nm}$. These are the third, second and the first harmonics of neodymium-doped yttrium aluminium garnet (Nd:YAG) laser, which is commonly used in both Raman lidar [36] and high spectral resolution lidar [37] instruments (see also [38,39]).

The single scattering calculations were performed with the discrete dipole approximation (DDA) code ADDA (version 1.2) [40]. In the DDA method the scatterer is divided into small fully polarisable volume elements (dipoles) in order to solve the volume integral equation of the scattering problem. This leads to a set of linear equations, which can be solved using numerical standard methods. An account of the DDA method can be found in [41,42]. By dividing the scatterer into small dipoles the DDA method can treat arbitrarily shaped particles. The dipole spacing $d$ was chosen so that $|m| k d=0.33$ for $355 \mathrm{~nm}$, with $|m|$ being the absolute value of the refractive index of soot and $k$ is the wavenumber of light. For $532 \mathrm{~nm}$ and $1064 \mathrm{~nm}$ the same dipole spacing was used, which resulted in $|m| k d=0.22$ and $|m| k d=0.12$, respectively. ADDA performs numerical orientation averaging of the target using discrete orientations [40]. For each scatterer 1024 orientations were used.

To determine the particle size ADDA requires the volume-equivalent radius as input. For bare aggregates with monomers in point-contact the number of monomers $N$ and the monomer radius 
$a_{\text {mon }}$ are related to the volume equivalent radius by

$$
r_{\mathrm{ve}, \mathrm{bare}, \mathrm{pc}}=a_{\mathrm{mon}} N^{\frac{1}{3}}
$$

However, overlapping monomers reduces the actual volume of each monomer and thereby the whole aggregate, thus the volume equivalent radius is adjusted by

$$
r_{\mathrm{ve}, \text { bare, ov }}=r_{\mathrm{ve}, \text { bare, } \mathrm{pc}}\left(1-K_{\mathrm{ov}}\right)^{\frac{1}{3}}
$$

The adjustment term is derived from geometrical considerations and expressed by

$$
K_{\mathrm{ov}}=\frac{C_{\mathrm{ov}}^{2}}{2}\left(3-C_{\mathrm{ov}}\right)
$$

The volume equivalent radius of a coated aggregate can then by calculated by

$$
r_{\mathrm{ve}, \text { coat }}=\frac{r_{\mathrm{ve}, \mathrm{bare}, \mathrm{ov}}}{f_{\mathrm{vol}}^{\frac{1}{3}}},
$$

where $f_{\text {vol }}$ denotes the soot volume fraction in the particle. Combining Eqs. (4)-(7) yields:

$$
r_{\mathrm{ve}, \mathrm{coat}}=a_{\mathrm{mon}}\left(\frac{N}{f_{\mathrm{vol}}}\left(1-\frac{C_{\mathrm{ov}}^{2}}{2}\left(3-C_{\mathrm{ov}}\right)\right)\right)^{\frac{1}{3}}
$$

ADDA gives the complete Mueller scattering matrix and the extinction and absorption cross sections and efficiencies for the scattering particles. With the help of the scattering matrix and the optical cross sections it is possible to compute other quantities of interest such as the linear backscattering depolarisation ratio and the extinction-to-backscatter ratio.

The linear backscatttering depolarisation ratio ratio can be calculated by [8]:

$$
\delta_{l}=\left.\frac{F_{11}-F_{22}}{F_{11}+F_{22}}\right|_{\vartheta=180^{\circ}}
$$

$F_{11}$ and $F_{22}$ denote the $(1,1)$ and the $(2,2)$ elements, respectively, of the Stokes scattering matrix. The expression is evaluated at the scattering angle $\vartheta=180^{\circ}$.

The lidar extinction coefficient can be calculated from the extinction cross section $C_{\mathrm{ext}}$ and the particle number density per size interval $n(r)$ by [43]

$$
\alpha=\int_{r_{\min }}^{r_{\max }} C_{\mathrm{ext}}(r) n(r) d r,
$$

where $r_{\min }$ and $r_{\max }$ denote, respectively, the smallest and the largest particle radius in the aerosol ensemble.

The lidar backscatter coefficient can be calculated from the scattering cross section $C_{\text {sca }}$, the $(1,1)$ element of the Stokes scattering matrix $F_{11}$, and $n(r)$ by [43]

$$
\beta=\int_{r_{\min }}^{r_{\max }} C_{\mathrm{sca}}(r) \frac{F_{11}\left(r, 180^{\circ}\right)}{4 \pi} n(r) d r
$$

In this study the smallest aggregate consists of $N=26$ monomers and the largest aggregate consists of $N=1508$ monomers, by inserting these values and $f_{v o l}$ into Eq. (8) $r_{\min }=191 \mathrm{~nm}$ and $r_{\max }=739 \mathrm{~nm}$ were calculated. 
In this study the particle number density per size interval $n(r)$ is assumed to follow a log-normal distribution described by the mean $\mu$ and the standard deviation $\sigma$ of the logarithmic variable:

$$
n(r)=\frac{N_{0}}{\sigma r \sqrt{2 \pi}} \exp \left(-\frac{(\ln r-\mu)^{2}}{2 \sigma^{2}}\right)
$$

The total number density of particles is $N_{0}$.

The extinction-to-backscatter ratio, which, in the context of lidar remote sensing, is frequently referred to as the lidar ratio, can be calculated for a distinct particle size as [43]

$$
S_{p}(r)=\left.4 \pi \frac{C_{\mathrm{ext}}(r)}{C_{\mathrm{sca}}(r) F_{11}(r)}\right|_{\vartheta=180^{\circ}}
$$

For an ensemble of different particle sizes the extinction-to-backscatter ratio $S_{p}$ can be calculated from the extinction coefficient (Eq. (10)) and the backscatter coefficient (Eq. (11)) [43]:

$$
S_{p}=\frac{\alpha}{\beta}
$$

Both $\delta_{l}$ and $S_{p}$ are independent of the total number density of particles $N_{0}$.

Spectral changes of extinction, backscattering, and extinction-to-backscatter ratio between two wavelengths $\lambda_{1}$ and $\lambda_{2}$ (with $\lambda_{1}<\lambda_{2}$ ) can be quantified using the Ångström-exponent [39]:

$$
{\stackrel{\circ}{a}, \lambda_{1}, \lambda_{2}}=\frac{\ln \left(x_{1} / x_{2}\right)}{\ln \left(\lambda_{2} / \lambda_{1}\right)}
$$

For $x$ either the extinction coefficient $\alpha$ (Eq. (10)), the backscattering coefficient $\beta$ (Eq. (11)) or the extinction-to-backscatter ratio $S_{p}$ (Eq. (13)) can be inserted. The Ångström exponents are related by: $\mathrm{a}_{\alpha, \lambda_{1}, \lambda_{2}}=\mathrm{a}_{\beta, \lambda_{1}, \lambda_{2}}+\mathrm{a}_{S, \lambda_{1}, \lambda_{2}}$ [44]. While the calculation of $\alpha$ and $\beta$ requires the total particle number density $N_{0}$, the Ångström exponent is independent of $N_{0}$.

In some studies (e.g. [45-49]) the spectral behaviour was quantified using the color ratio $C R$, which is defined as $C R=x_{2} / x_{1}$ with $x$ being either the extinction-to-backscatter ratio $S_{p}$ or the backscatter coefficient $\beta$ at $\lambda_{1}$ and $\lambda_{2}$, respectively (with $\lambda_{1}<\lambda_{2}$ ). As the color ratio can be easily converted into the corresponding Ångström exponent it will not be specifically covered in this study.

So far only few measurements of the depolarisation ratio of soot particles at $\lambda=1064 \mathrm{~nm}$ have been reported $[38,39,50]$ and even fewer measurements of the extinction-to-backscatter ratio [39]. As using the depolarisation ratio at $\lambda=1064 \mathrm{~nm}$ improves the retrieval of aerosol microphysics [51] the calculation for this wavelength was included in our study.

\section{Results}

Figure 2 shows the linear depolarisation ratio (top row) and extinction-to-backscatter ratio (bottom row) for the different particle sizes at $355 \mathrm{~nm}$ (left column), $532 \mathrm{~nm}$ (middle column) and 1064 $\mathrm{nm}$ (right column). The colored line indicates the arithmetic mean over five different stochastic realisations of the aggregates and the shading in lighter colors indicates ranges of values caused by these different stochastic realisations. The arithmetic mean is indicated by a bar over the symbol, e.g. $\bar{\delta}_{l}$. Note the different ranges of depolarisation ratio indicated by the y-axes in the top row and the non-linearity of the volume-equivalent radius indicated by the $\mathrm{x}$-axis at the top of each sub-figure.

For both coating materials there is a change in both number and magnitude of the resonances of the depolarisation ratio. With increasing wavelength both the number and the magnitude of the resonances in the range between $N=26$ and $N=1508$ decreases. The depolarisation ratios at $355 \mathrm{~nm}$ cover a range from $0-30 \%$, at $532 \mathrm{~nm}$ from $0-8.5 \%$ and from $0-5 \%$ at $1064 \mathrm{~nm}$. 

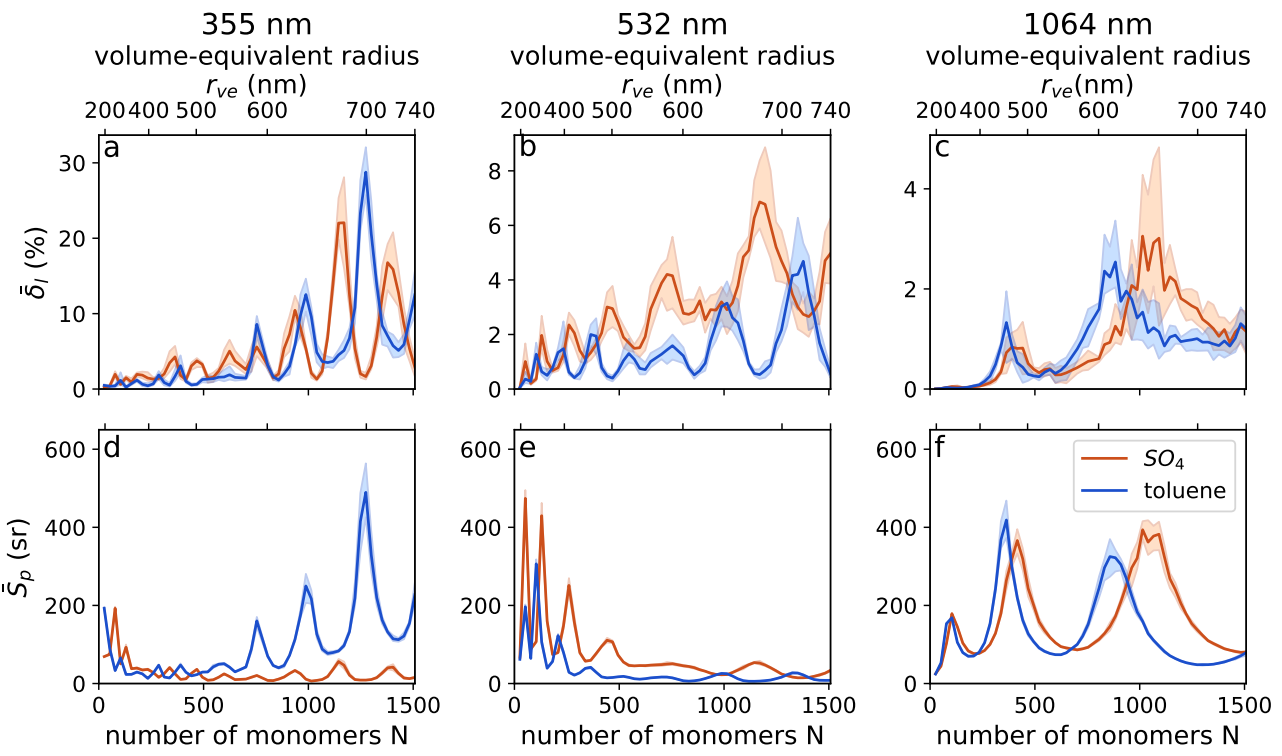

Fig. 2: Linear depolarisation ratio (a-c) and extinction-to-backscatter ratio (d-f) for sulphate coating (red/light red) and toluene-based coating (blue/light blue) for $355 \mathrm{~nm}$ (a, d), $532 \mathrm{~nm}$ $(b, e)$ and $1064 \mathrm{~nm}(\mathrm{c}, \mathrm{f})$. The arithmetic mean over five different stochastic realisations of the aggregates is shown in red and blue, respectively. The shading indicate the range due to different stochastic realisations of the aggregate structure.

In [23] similar resonances for the extinction-to-backscatter ratio are reported, whereas the reported resonances in the depolarisation ratio are of smaller magnitude.

There are noticeable differences in magnitude of both depolarisation ratio and extinction-tobackscatter ratio for the different coating materials at $355 \mathrm{~nm}$ and $532 \mathrm{~nm}$, while at $1064 \mathrm{~nm}$ the differences in magnitude are less pronounced. This indicates that linear depolarisation ratio and extinction-to-backscatter ratio with more pronounced differences may provide the possibility to distinguish between coating materials at $355 \mathrm{~nm}$ and $532 \mathrm{~nm}$.

The extinction-to-backscatter ratio at $532 \mathrm{~nm}$ (see Fig. 2e), shows higher values for the nonabsorbing sulphate coating than for the mildly absorbing toluene-based coating. Higher values of the extinction-to-backscatter ratio can be caused by higher absorption or lower backscattering (e.g. [24]). To understand why the extinction-to-backscatter ratio at $\lambda=0.532 \mathrm{~nm}$ for sulphate coating is higher than for toluene, despite having a lower imaginary part of the refractive index, the optical cross sections at this wavelength are examined more closely.

Figure 3 shows backscattering ( $C_{\text {bak }}$, top), extinction $\left(C_{\text {ext }}\right.$, centre) and absorption cross section $\left(C_{\mathrm{abs}}\right.$, bottom) at $\lambda=532 \mathrm{~nm}$ of the coated aggregates for sulphate coating (red) and toluene-based coating (blue). For each individual size (expressed in number of monomers) the aggregates differ only in the refractive index of the coating material. Note the non-linearity of the volume-equivalent radius given at the top of the figure.

As can be seen in the top panel of Fig. 3 with exceptions at $N \sim 100\left(r_{\mathrm{ve}} \sim 300 \mathrm{~nm}\right), N \sim 200$ $\left(r_{\mathrm{ve}} \sim 380 \mathrm{~nm}\right), N \sim 1000\left(r_{\mathrm{ve}} \sim 640 \mathrm{~nm}\right)$ and $1300 \leq N \leq 1400\left(700 \mathrm{~nm} \leq r_{v e} \leq 720 \mathrm{~nm}\right)$ the backscattering cross section for aggregates with toluene-based coating is larger than that of sulphate coated aggregates. These four size intervals coincide with the intervals at which the extinction-to-backscatter ratio of aggregates with toluene-based coating exceeds the extinctionto-backscatter ratio of sulphate-coated aggregates, as can be seen in Fig. 2. 

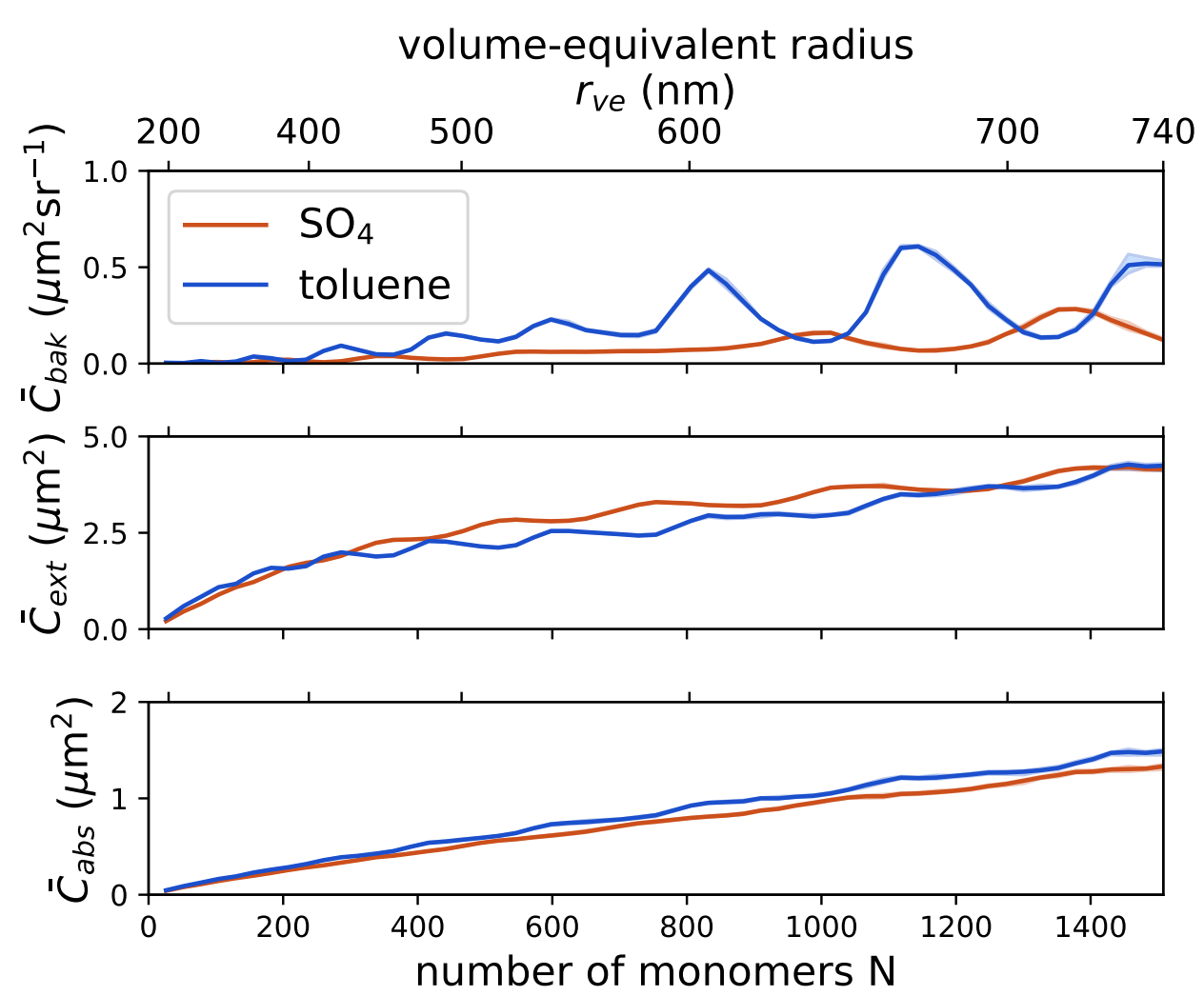

Fig. 3: Backscattering ( $C_{\text {bak }}$, top), extinction $\left(C_{\text {ext }}\right.$, centre $)$ and absorption cross section $\left(C_{\text {abs }}\right.$, bottom) of the coated aggregates for sulphate coating (red) and toluene-based coating (blue) in $\mu \mathrm{m}^{2}$ (for $C_{\text {ext }}$ and $C_{\text {abs }}$ ) and $\mu \mathrm{m}^{2} \mathrm{sr}^{-1}$ (for $C_{\text {bak }}$ ) at $\lambda=532 \mathrm{~nm}$. Solid lines indicate the mean over the five different stochastic realisations and the shading the maximum uncertainty due to the different realisations of the stochastic geometries (The differences for the extinction and absorption cross section are too small to be distinguished from the mean).

The bottom panel shows the absorption cross section. Corresponding to the higher value of the imaginary part of the refractive index the absorption cross section for the aggregates coated with toluene-based material is higher than that of the sulphate-coated aggregates.

Comparing the extinction, absorption and backscattering cross section at $\lambda=532 \mathrm{~nm}$ (Fig. 3) to the extinction-to-backscatter ratio at $\lambda=532 \mathrm{~nm}$ (Fig. 2) shows that the difference in extinctionto-backscatter ratio for the two coating materials can be attributed to higher backscattering cross sections of the aggregates coated with toluene-based material despite the higher absorption cross sections.

Comparing the extinction-to-backscatter ratios at $355 \mathrm{~nm}, 532 \mathrm{~nm}$, and $1064 \mathrm{~nm}$ with each other (see Fig. 2d-f), shows that the extinction-to-backscatter ratio's minimum values are larger at $1064 \mathrm{~nm}$ than at $355 \mathrm{~nm}$ and $532 \mathrm{~nm}$, as well as there more comparatively small values for $S_{p, 355}$ and $S_{p, 532}$ than for $S_{p, 1064}$. Analogous to Fig. 3 Fig. 4 shows backscattering ( $C_{\text {bak }}$, top), extinction $\left(C_{\text {ext }}\right.$, centre $)$ and absorption cross section $\left(C_{\mathrm{abs}}\right.$, bottom) at $355 \mathrm{~nm}$ (left column) and at $1064 \mathrm{~nm}$ (right column). Note the different value ranges of the y-axes.

A comparison between the backscattering $\left(C_{\text {bak }}\right)$, extinction $\left(C_{\text {ext }}\right)$ and absorption cross sections 
$355 \mathrm{~nm}$

volume-equivalent radius
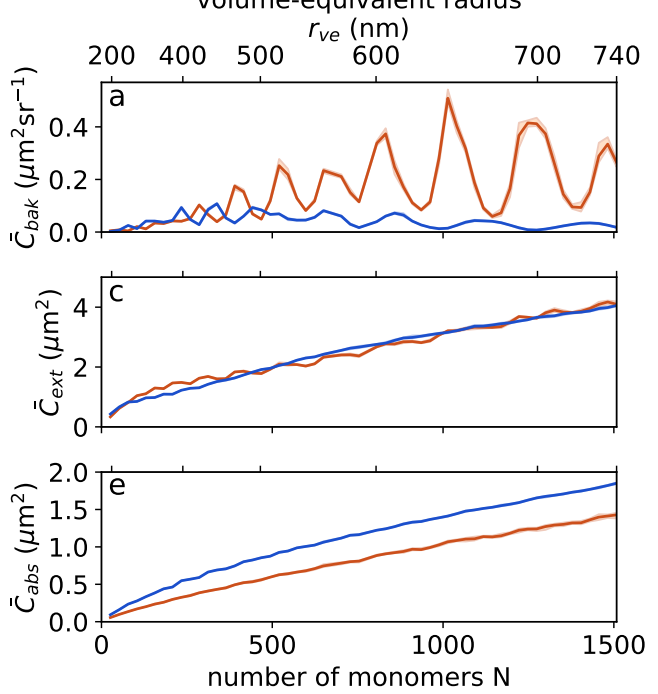

$1064 \mathrm{~nm}$

volume-equivalent radius
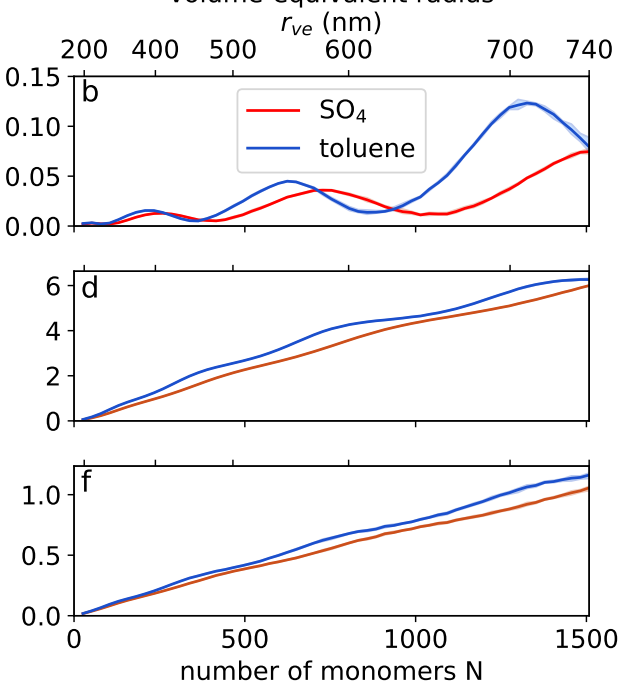

Fig. 4: As Fig. 3, but for 355 nm (a,c,e) and 1064 nm (b,d,f).

$\left(C_{\text {abs }}\right)$ for each wavelength (Figs. 3 and 4 ) shows, that the backscattering cross sections at $355 \mathrm{~nm}$ and $532 \mathrm{~nm}$ cover ranges between $0-0.6 \mu \mathrm{m}^{2} \mathrm{sr}^{-1}$ and $0-0.5 \mu \mathrm{m}^{2} \mathrm{sr}^{-1}$ respectively. However, the backscattering cross sections at $1064 \mathrm{~nm}$ cover a smaller range, $0-0.12 \mu \mathrm{m}^{2} \mathrm{sr}^{-1}$. The low values of $C_{\text {bak }}$ at $355 \mathrm{~nm}$ for aggregates with toluene-based coating and more than $N \sim 700$ monomers coincide with the large values of $S_{p, 355}$.

So far the spectral differences were considered for a set of differently sized individual particles. Particles measured in the field with remote sensing instruments always follow a size distribution. In agreement with the field measurements reported in [17] the soot particles were assumed to follow a log-normal distribution. As a reference we choose a mean of $m=498$ and a standard deviation of $s=995$ monomers per aggregate (see reported values for sample A1 in [17]). To give an estimate of uncertainty due to changes in the particle size distribution, we (i) vary the mean between values from 300 to 700 monomers per aggregate while keeping the standard deviation fixed at $s=995$; and (ii) vary the standard deviation between 300 and 1350 monomers per aggregate while keeping the mean fixed at $m=498$. The ensemble-mean of the resulting values of the extinction-to-backscatter ratio and the depolarisation ratio for each wavelength are reported in Table 3. The given uncertainty estimates are based on the largest deviation from the reference case for each quantity and wavelength.

To gauge the computational results, Tables 5 and 6 list results from lidar field observations. The range of mean values and the range of extreme values derived from these two tables are summarised in Table 3 in the second to last and the last row, respectively. By extreme values we mean the maximum and the minimum of all mean values \pm one standard deviation. The comparison of computational results with the field observations is discussed in Sect. 4

The differences in the complex refractive index (reflecting the differences in chemical composition) of the coating material are listed in Table 2. As stated above, at $355 \mathrm{~nm}$ and 532 $\mathrm{nm}$ the toluene-based coating is mildly absorbing and the sulphate coating is purely scattering, while at $1064 \mathrm{~nm}$ the sulphate coating is weakly absorbing whereas the toluene-based coating is purely scattering. The differences in extinction-to-backscatter ratio at $355 \mathrm{~nm}$ are likely to be explained by this difference in the imaginary part of the complex refractive index. 
Table 3: calculated linear depolarisation ratio and extinction-to-backscatter-ratio for the two coating materials, and range of reported mean values from lidar field measurements, as well as range of reported extreme values (see Tables 5 and 6 for a more detailed overview of reported values and the corresponding references).

\begin{tabular}{lllllll} 
coating & $\delta_{l, 355}(\%)$ & $\delta_{l, 532}(\%)$ & $\delta_{l, 1064}(\%)$ & $S_{p, 355}(s r)$ & $S_{p, 532}(\mathrm{sr})$ & $S_{p, 1064}(\mathrm{sr})$ \\
\hline sulphate & $3.39 \pm 0.57$ & $2.84 \pm 0.29$ & $0.86 \pm 0.16$ & $19.66 \pm 4.45$ & $57.35 \pm 8.49$ & $130.49 \pm 9.61$ \\
toluene & $1.68 \pm 0.34$ & $1.13 \pm 0.15$ & $0.82 \pm 0.10$ & $35.69 \pm 2.77$ & $20.12 \pm 4.95$ & $106.12 \pm 12.37$ \\
\hline $\begin{array}{l}\text { reported medium } \\
\text { reported } \min / \max \end{array}$ & $1.0-28.0$ & $2.3-20.0$ & $0.9-5.0$ & $21-114$ & $26-100$ & $82-92$ \\
& $0.8-28$ & $2.0-23$ & $0.1-5$ & $13-147$ & $26-130$ & $60-119$
\end{tabular}

Table 4 lists the extinction, backscattering and extinction-to-backscatter Ångström exponents between 355 and 532nm, and between 532 and $1064 \mathrm{~nm}$. For $\lambda_{1}<\lambda_{2}$ the denominator of the Ångström exponent (Eq. (15)) is always positive. Thus a positive value of the Ångström exponent indicates that the quantity (either $\alpha, \beta$ or $\mathrm{S}$ ) decreases from $\lambda_{1}$ to $\lambda_{2}$. Negative values indicate an increase, and no spectral change give values of zero.

Additionally to these Ångström exponents, which can be measured with lidar instruments, the absorption Ångström exponent (AAE) was calculated by inserting $C_{\text {abs }}$ into Eq. (15). The AAE can be usually measured using sun photometers and radiometers [52-54]. For sulphate coating the AAE between 355 and $532 \mathrm{~nm}$ was calculated to be $\mathrm{AAE}_{355,532}=0.29 \pm 0.04$ and the AAE between 532 and $1064 \mathrm{~nm}$ was $\mathrm{AAE}_{532,1064}=0.51 \pm 0.06$. For toluene-based coating the AAE between the two wavelength pairs 355 and $532 \mathrm{~nm}$, and 532 and $1064 \mathrm{~nm}$ was found to be $\mathrm{AAE}_{355,532}=0.98 \pm 0.08$ and $\mathrm{AAE}_{532,1064}=0.52 \pm 0.06$. Commonly the AAE obtained from field measurements is reported for different wavelength pairs (see [52-54] and references therein.) For this reason we refrain from a comparison of our calculated values of the AAE with the values reported from field measurements.

Table 7 lists Ångström exponents based on lidar field measurements. Entries marked with * indicate values not directly reported, but calculated from reported values of $\alpha$, $\mathrm{a}_{\alpha}$ and/or $S_{p}$. The range of mean and extreme values based on Table 7 are summarised in the last two rows of Table 4.

Table 4: calculated Ångström exponents of extinction, backscattering and extinction-tobackscatter-ratio between 355 and $532 \mathrm{~nm}$ and 532 and $1064 \mathrm{~nm}$, and range of reported mean values from lidar field measurements, as well as range of reported extreme values (see Table 7 for a more detailed overview of reported values and the corresponding references).

\begin{tabular}{|c|c|c|c|c|c|c|}
\hline coating & $\stackrel{\circ}{a}_{\alpha, 355,532}$ & $\stackrel{\mathrm{a}}{\alpha, 532,1064}$ & $\stackrel{\circ}{\beta, 355,532}$ & 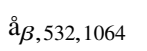 & $\mathrm{a}_{S, 355,532}$ & $\mathrm{å}_{S, 532,1064}$ \\
\hline sulphate & $-0.35 \pm 0.21$ & $0.30 \pm 0.17$ & $2.31 \pm 0.26$ & $1.49 \pm 0.12$ & $-2.66 \pm 0.42$ & $-1.19 \pm 0.29$ \\
\hline toluene & $-0.35 \pm 0.03$ & $-0.04 \pm 0.23$ & $-1.78 \pm 0.55$ & $2.37 \pm 0.23$ & $1.43 \pm 0.54$ & $-2.41 \pm 0.41$ \\
\hline reported mean & $-0.3-2.2$ & $0.6-0.85$ & $-0.58-3.09$ & $-0.65-1.80$ & $-3.58-1.16$ & $-0.48--0.29$ \\
\hline reported $\min / \max$ & $-0.7-2.9$ & $0.3-1.15$ & $-0.82-3.44$ & $-0.96-2$ & $-3.7-2.52$ & $-1.22-0.24$ \\
\hline
\end{tabular}

\section{Discussion}

The uncertainty estimates for $\delta_{l}$ in [21] showed that for thickly coated soot particles the optical properties are very sensitive to a variation in the refractive index of the coating material. Our 
aim is to assess the possibility of exploiting this sensitivity to distinguish between coating materials using lidar-measureable quantities. The lidar observables in question are $\delta_{l}, S_{p}$, and the Ångström exponents $\stackrel{\circ}{\alpha}_{\alpha}, \stackrel{a}{\beta}_{\beta}$, and $\mathrm{a}_{S}$. The computations suggest that the potential of extracting information on the coating material varies greatly among these observables. In order to extract such information from any given observable, it is required that the estimated uncertainty range is smaller than the sensitivity to the composition of the coating material. For instance, the ensemble-averaged values of $\delta_{l}$ and $S_{p}$ for sulphate and toluene-based coating are distinctly separated, with the exception of $\delta_{l}$ at $1064 \mathrm{~nm}$ (see Table 3).

Spectral changes of extinction, backscattering and extinction-to-backscatter ratio can be quantified by the Ångström exponent (see Eq. (15)). The numerical value of the Ångström

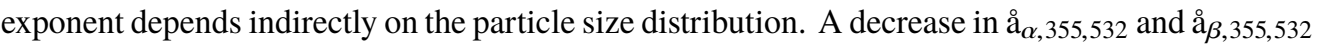
indicates a size distribution increasingly dominated by larger particles, i.e. the median diameter increases [44,55]. Thus the aerosol Ångström exponent is sensitive to the choice of particle size distribution. The calculated values of $\mathrm{a}_{\alpha, 355,532}$ for toluene-based coating and of $\mathrm{a}_{\beta, 355,532}$ for sulphate coated soot aerosol show small relative uncertainties below $10 \%$. In view of the strong size-dependence of the Ångström exponent these small relative uncertainties are somewhat surprising. Relative uncertainties of below $10 \%$ are also observed for $\mathrm{a}_{\beta, 532,1064}$. For larger wavelengths included in the wavelength pair the value of the Ångström exponent does not show a clear dependence on the size distribution [55].

The extinction Ångström exponent computed for the two coating materials strongly overlap. The mean values of $\stackrel{a}{\alpha}_{\alpha}$ for sulphate and toluene-based coating between $355 \mathrm{~nm}$ and $532 \mathrm{~nm}$ are indistinguishable. Additionally, the ranges of the $532 \mathrm{~nm}$ and $1064 \mathrm{~nm}$ wavelength pair partially overlap. For the $355 \mathrm{~nm}$ and $532 \mathrm{~nm}$ as well as the $532 \mathrm{~nm}$ and $1064 \mathrm{~nm}$ wavelength pair the ranges of $\stackrel{a}{\beta}_{\beta}$ and $\AA_{S}$ for the two coating materials do not overlap (see Table 4). The strong overlap between the ranges of $\mathrm{a}_{\alpha, 355,532}$ for sulphate and toluene-based coating confirms previous findings. $\stackrel{\circ}{\alpha}_{\alpha}$ is considered less sensitive to changes in the refractive index than $\mathrm{a}_{\beta}$, especially for changes in the imaginary part of the refractive index [56].

The spectral behaviour of the backscattering coefficient and the extinction-to-backscatter ratio between $355 \mathrm{~nm}$ and $532 \mathrm{~nm}$ shows major differences between the two coating materials: Between $355 \mathrm{~nm}$ and $532 \mathrm{~nm}$ the backscattering coefficient of the sulphate coated aggregates decreased, as is reflected by the positive value of the corresponding Ångström exponent $\left(\mathrm{a}_{\beta, 355,532}\left(\mathrm{SO}_{4}\right)=\right.$ $2.31 \pm 0.26)$. In case of toluene-based coating the backscattering coefficient increases between 355 $\mathrm{nm}$ and $532 \mathrm{~nm}\left(\stackrel{\circ}{a}_{\beta, 355,532}\right.$ (toluene $\left.)=-1.78 \pm 0.55\right)$. The extinction-to-backscatter ratio increases for sulphate coating from $355 \mathrm{~nm}$ to $532 \mathrm{~nm}\left(\mathrm{a}_{S, 355,532}\left(\mathrm{SO}_{4}\right)=-2.66 \pm 0.42\right)$ and decreases in case of toluene-based coating ( $\stackrel{\circ}{S}, 355,532$ (toluene $)=1.43 \pm 0.54)$. Thus, the differences in spectral behaviour of $\beta$ and $S_{p}$ between $355 \mathrm{~nm}$ and $532 \mathrm{~nm}$, which are quantified by å $\mathrm{a}_{\beta, 355,532}$

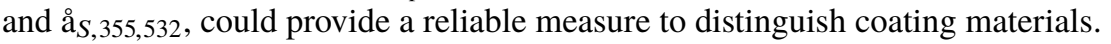

The ranges of $\delta_{l, 1064}$ and $a_{\alpha}$ for sulphate and toluene-based coating overlap, which means that measuring $\delta_{l, 1064}$ and $\mathrm{a}_{\alpha}$ adds limited value for distinguishing coating materials. However, the coating material-dependent differences in all other quantities are sufficiently large, so the ranges do not overlap and may allow for a distinction of coating material.

The overlap of the ranges of $\delta_{l, 1064}$, however, does not invalidate the finding reported in [51], which analysed the benefit of $\delta_{l, 1064}$-measurements for microphysical retrievals. According to [51], additional measurements of $\delta_{l, 1064}$ help in constraining the effective particle size and the mass concentration. Similarly, the limited value of $\stackrel{a}{\alpha}_{\alpha}$ for distinguishing between coating materials does not question the benefit of these measurements for retrieving other microphysical properties.

Field observations of $\delta_{l}, S_{p}$ and Ångström exponents of soot-containing aerosol are listed in Tables 5, 6, and 7, respectively. The ranges of mean, maximum, and minimum values are summarised in Table 3 and 4 . The computational results for sulphate fall within the range of field 
observations, with the exception of $S_{p}, 1064$. For toluene several of the Ångström exponents are out of range. This may indicate that coating materials with the spectral behaviour of pure toluene are not frequently found in the field. We also see that most computational results for $\delta_{l}$ lie at the lower end of the field observations. This can be explained by the choice of the free parameter in the model, $D_{c}$, which has been set to $D_{c}=0.6 D_{\max }$ and $D_{c}=0.8 D_{\max }$. For the assumed soot volume fraction of $f_{\mathrm{vol}}=0.07$ this yields aggregates embedded in a spherical coating shell (see Fig. 1). This results in small depolarisation ratios. By choosing a larger critical diameter, we would obtain a realisation of our model that would give rise to higher values of the linear depolarisation ratio in the backscattering direction, as discussed in [21]. A homogeneous spheroidal particle model of mineral dust was found to give larger values of $S_{p}$ at $532 \mathrm{~nm}$ than a spherical particle model [12]. This indicates that a choice of a larger value of $D_{c}$ might increase the values of $S_{p}$, too.

Field observations can serve as an approximate gauge for computational results. However, it is important to emphasise that such comparisons need to to be taken with a grain of salt. Our computations were based on specific assumptions on the size distribution, soot volume fraction, morphology, and composition of the coating. Such detailed a priori information is often lacking when interpreting field measurements. Further, it can prove difficult to determine whether or not aerosol plumes in the field consist purely of soot-containing aerosol or if other types, such as dust, have been mixed into the plume. For this reason, Tables 3 and 4 only provide a rough indication, but certainly not a robust comparison of model results with measurements. A more detailed comparison or even tuning of the model would have to rely on laboratory measurements that provide a comprehensive characterisation of the microphysical, compositional, and optical properties of the particles.

With exception of the field measurements of the depolarisation ratio reported in [38], all field measurements listed in Tables 5-7 were obtained with Raman lidar instruments using the respective Raman retrieval technique [57,58]. Profiles of the depolarisation ratio are commonly obtained using the retrieval method discussed in [59]. The depolarisation ratios reported in [38] were obtained using a High Spectral Resolution Lidar using the retrievals discussed in $[38,60]$. The typical relative measurement uncertainties for extinction coefficients and backscatter coefficients during night-time measurements derived with the corresponding Raman retrieval technique is $\sim 10 \%$ and $\sim 20 \%$ for day-time measurements. The typical relative uncertainty of the retrieved linear depolarisation ratio is $\sim 3 \%$ during night-time and $\sim 10 \%$ during day-time [61]. The relative uncertainty of the linear depolarisation ratio presented in [38], which was retrieved with an HSRL instrument, ranges between 2.6\% (at $1064 \mathrm{~nm}$ ) and 5.0\% (at $532 \mathrm{~nm}$ ). In addition to the uncertainty associated with the retrieval process, the uncertainties given in Tables 5-7 contain standard deviations of values within the analysed aerosol layer.

The aerosol types as well as the age given in Tables 5-7 were taken from the respective reference. The types smoke and biomass burning aerosol were assumed to refer to (coated) soot particles. The determination of the aerosol type relies of the combination of satellite data (both images and derived aerosol types) (e.g., [46, 47, 62-64]), comparisons with previous measurements (e.g., [46]), and numerical calculations of backward trajectories and dispersion (e.g., $[46,62,64,65])$. The age of the smoke and biomass burning aerosol is inferred from backward trajectories, however, the age as indicated in Tables 5-7 is not necessarily consistent between the different studies. For example aerosol plumes, which are 2-3 days old are classified as moderately fresh in [48], while they referred to as aged in [66].

No clear spectral behaviour of $S_{p}$ between $355 \mathrm{~nm}$ and $532 \mathrm{~nm}$ can be inferred from the reported field measurements listed in Table 5 , which is reflected by the range of ås,355,532. An increase of $S_{p}$ between $355 \mathrm{~nm}$ and $532 \mathrm{~nm}$ as reported in $[39,46,50,61,62,66,68,70,71]$ is qualitatively consistent with the results for sulphate-coated particles (see Table 3 ). The decrease for the same wavelength range as reported in $[48,62,66,67,69]$ is qualitatively consistent with the 
Table 5: Spectral values of the extinction-to-backscatter ratio reported from lidar field measurements. Type refers to the classification in the cited reference. Biomass burning aerosol (BBA) and (aged) smoke are assumed to refer to (coated) soot particles.

\begin{tabular}{|c|c|c|c|c|c|}
\hline type & location & $S_{p, 355}(s r)$ & $S_{p, 532}(\mathrm{sr})$ & $S_{p, 1064}(\mathrm{sr})$ & reference \\
\hline smoke & Manaus, Brazil & $62 \pm 12$ & $64 \pm 15$ & - & {$[64]$} \\
\hline smoke & Praia, Cape Verde & $87 \pm 17$ & $79 \pm 17$ & - & {$[67]$} \\
\hline smoke & Manaus, Brazil & $40-50$ & $60-70$ & - & {$[68]$} \\
\hline BBA & Praia, Cape Verde & $87 \pm 8$ & $67 \pm 5$ & - & {$[62]$} \\
\hline BBA & Praia, Cape Verde & $64 \pm 7$ & $86 \pm 8$ & - & {$[62]$} \\
\hline BBA & Elandsfontein, South Africa & $92 \pm 10$ & $75 \pm 14$ & - & [69] \\
\hline smoke & Gwangju, Korea & $56 \pm 7$ & $63 \pm 7$ & - & {$[70]$} \\
\hline aged smoke & Leipzig, Germany & $46 \pm 6$ & $67 \pm 4$ & $82 \pm 22$ & [39] \\
\hline aged smoke & Leipzig, Germany & $40 \pm 16$ & $66 \pm 12$ & $92 \pm 27$ & [39] \\
\hline aged smoke & Granada, Spain & $23 \pm 10$ & $47 \pm 11$ & - & {$[46]$} \\
\hline aged smoke & Leipzig, Germany & $25 \pm 4$ & $51 \pm 9$ & - & {$[46]$} \\
\hline aged smoke & Warsaw, Poland & $34 \pm 6$ & $58 \pm 10$ & - & {$[46]$} \\
\hline smoke & Tokio, Japan & $\sim 40$ & $\sim 65$ & - & [71] \\
\hline aged smoke & Leipzig, Germany & $21-67$ & $26-87$ & - & {$[65]$} \\
\hline aged smoke & Warsaw, Poland & $60 \pm 20$ & $100 \pm 30$ & - & {$[61]$} \\
\hline aged smoke & Lille, France & $31-45$ & $54-58$ & - & {$[50]$} \\
\hline aged smoke & Palaiseau, France & $36 \pm 6$ & $58 \pm 7$ & - & {$[50]$} \\
\hline BBA & Granada, Spain & $60-65$ & $60-65$ & - & {$[72]$} \\
\hline BBA & Évora, Portugal & $56 \pm 6$ & $56 \pm 6$ & - & {$[63]$} \\
\hline fresh BBA & Magurele, Romania & $73.0 \pm 11.6$ & $45.7 \pm 6.4$ & - & {$[66]$} \\
\hline medium fresh BBA & Magurele, Romania & $42.9 \pm 6.8$ & $43.4 \pm 6.1$ & - & {$[66]$} \\
\hline aged BBA & Magurele, Romania & $41.1 \pm 6.6$ & $55.9 \pm 7.8$ & - & {$[66]$} \\
\hline aged BBA & Magurele, Romania & $48.4 \pm 7.7$ & $54 \pm 7.5$ & - & {$[66]$} \\
\hline aged BBA & Magurele, Romania & $31.7 \pm 5.0$ & $52.1 \pm 7.3$ & - & {$[66]$} \\
\hline aged BBA & Magurele, Romania & $35.0 \pm 5.6$ & $53.9 \pm 7.5$ & - & {$[66]$} \\
\hline fresh BBA & Évora, Portugal & $51 \pm 17$ & $54 \pm 28$ & - & [47] \\
\hline aged BBA & Évora, Portugal & $58 \pm 17$ & $56 \pm 25$ & - & [47] \\
\hline moderately fresh BBA & Warsaw, Poland & $76 \pm 7$ & $62 \pm 4$ & - & {$[48]$} \\
\hline fresh BBA & Warsaw, Poland & $81 \pm 6$ & $60 \pm 6$ & - & {$[48]$} \\
\hline moderately aged BBA & Warsaw, Poland & $71 \pm 10$ & $57 \pm 8$ & - & {$[48]$} \\
\hline fresh BBA & Warsaw, Poland & $114 \pm 33$ & $78 \pm 25$ & - & {$[48]$} \\
\hline moderately fresh BBA & Warsaw, Poland & $80 \pm 7$ & $66 \pm 9$ & - & {$[48]$} \\
\hline moderately aged BBA & Warsaw, Poland & $69 \pm 9$ & $61 \pm 7$ & - & {$[48]$} \\
\hline
\end{tabular}

results for aggregates with toluene-based coating. The spectral behaviour of the simulated $\delta_{l}$ for both coating types, i.e. decreasing with increasing wavelength, is, too, consistent with reported measurements, as can be inferred from Table 6 . While the spectral behaviour of $S_{p}$ reported in [48] is qualitatively consistent with the simulation results for aggregates toluene-based coating 
coating, the reported increase of $\delta_{l}$ from $355 \mathrm{~nm}$ to $532 \mathrm{~nm}$ is not consistent with the simulation results for aggregates with either sulphate or toluene-based coating.

Table 6: Spectral values of the linear depolarisation ratio reported from field measurements. Type refers to the classification in the cited reference. Biomass burning aerosol (BBA) and (aged) smoke are assumed to refer to (coated) soot particles.

\begin{tabular}{llllll} 
type & location & $\delta_{l, 355}(\%)$ & $\delta_{l, 532}(\%)$ & $\delta_{l, 1064}(\%)$ & reference \\
\hline aged smoke & Leipzig, Germany & $22.4 \pm 1.5$ & $18.4 \pm 0.6$ & $4.3 \pm 0.7$ & {$[39]$} \\
aged smoke & Leipzig, Germany & $2.1 \pm 4.0$ & $2.9 \pm 1.5$ & $0.9 \pm 0.8$ & {$[39]$} \\
aged smoke & Lille, France & $23-28$ & $18-20$ & $4-5$ & {$[50]$} \\
smoke & Denver, USA & $20.3 \pm 3.6$ & $9.3 \pm 1.5$ & $1.8 \pm 0.2$ & {$[38]$} \\
smoke & US east coast, USA & - & $6.8 \pm 1.0$ & $1.9 \pm 0.5$ & {$[38]$} \\
BBA & Praia, Cape Verde & $17 \pm 2$ & $16 \pm 1$ & - & {$[62]$} \\
BBA & Praia, Cape Verde & $23 \pm 2$ & $19 \pm 4$ & - & {$[62]$} \\
aged smoke & Warsaw, Poland & $5 \pm 2$ & $4 \pm 1$ & - & {$[61]$} \\
moderately fresh BBA & Warsaw, Poland & $1.6 \pm 0.2$ & $3.5 \pm 0.3$ & - & {$[48]$} \\
fresh BBA & Warsaw, Poland & $2.5 \pm 0.4$ & $5.0 \pm 0.3$ & - & {$[48]$} \\
moderately aged BBA & Warsaw, Poland & $1.0 \pm 0.2$ & $2.3 \pm 0.3$ & - & {$[48]$} \\
fresh BBA & Warsaw, Poland & $1.6 \pm 0.3$ & $3.8 \pm 0.5$ & - & {$[48]$} \\
moderately fresh BBA & Warsaw, Poland & $1.1 \pm 0.1$ & $2.8 \pm 0.1$ & - & {$[48]$} \\
moderately aged BBA & Warsaw, Poland & $1.0 \pm 0.1$ & $2.3 \pm 0.3$ & - & {$[48]$}
\end{tabular}

\section{Summary and conclusions}

The depolarisation ratio of thickly coated soot aggregates is known to be sensitive to the refractive index of the coating material [21]. The aim of this study was to investigate whether or not this sensitivity can be exploited for distinguishing among coating materials with the help of lidar-measureable quantities, such as linear depolarisation ratio, extinction-to-backscatter ratio and Ångström exponents.

The computational results suggest that both the linear depolarisation ratio and the extinctionto-backscatter ratio differ for the two different coating materials (sulphate and toluene-based organic coating) for thickly coated soot aggregates. The only exception is $\delta_{l}$ at a wavelength of $1064 \mathrm{~nm}$. In the model particles, the two different coating materials were not assumed to induce any morphological differences. Thus, the only cause for the differences in optical properties are differences in the refractive index, when comparing the results at the same wavelengths.

The spectral dependence of the optical properties may contain additional information on the

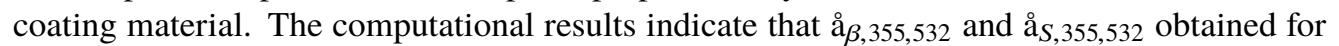
sulphate and toluene are clearly separated, and even have opposite signs. These may provide robust measures for distinguishing toluene-based coating from inorganic coating materials.

The refractive indices of different inorganic coating materials, such as nitrates, are very similar to that of sulphate [15]. On the other hand, the refractive index of organic coating material depends on precursor material and reaction conditions (i.e. ozone concentration or nitrate oxide concentration) $[32,35]$. The optical contrast between organic and inorganic coating is therefore 


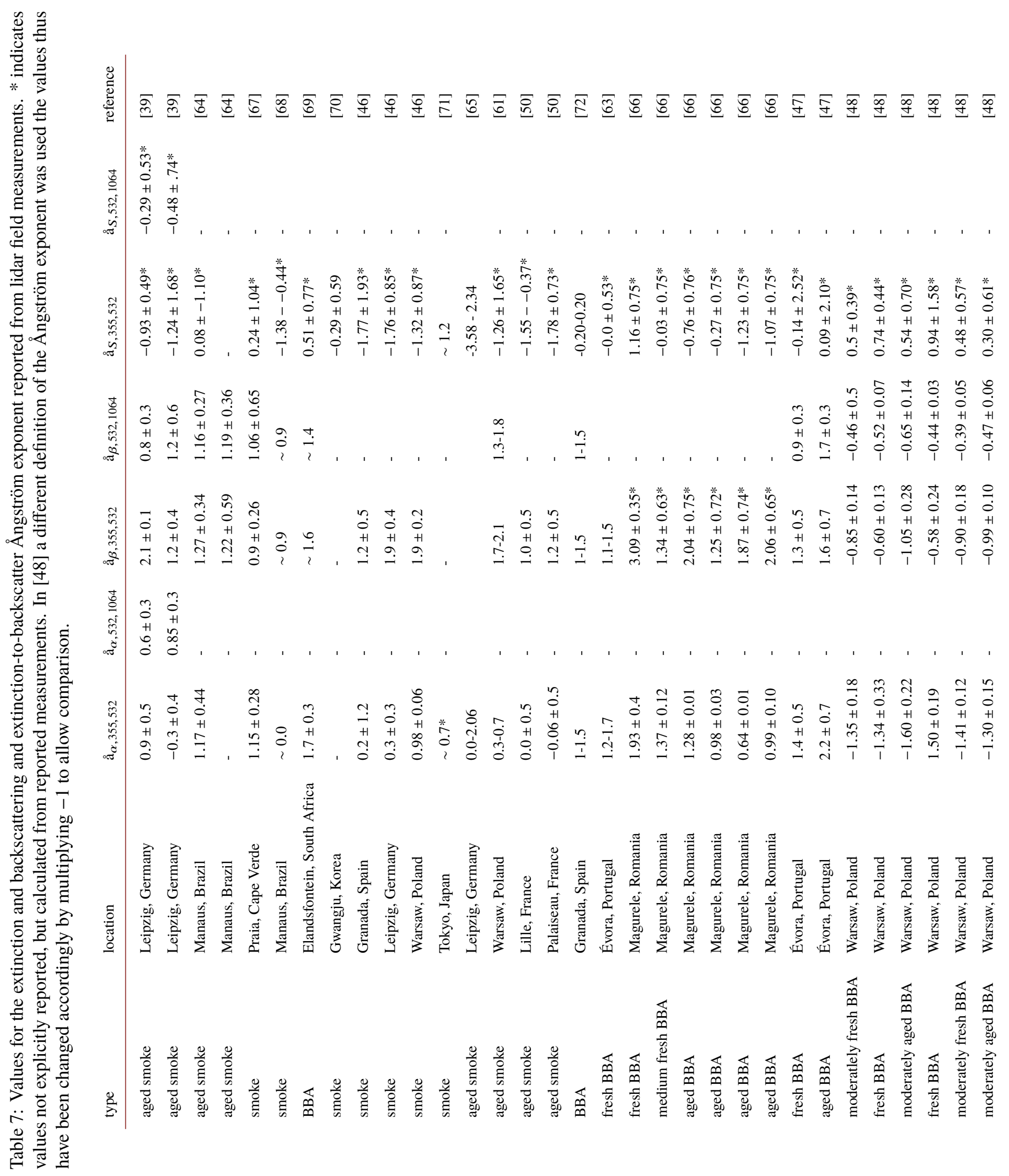


expected to vary. The discrepancies in Ångström exponents we found between toluene-based computations and measurements may indicate that the coating materials observed in the field have spectral dielectric properties that differ from those of pure toluene. It remains an open question for future studies to what extent and how other organic coating materials can be distinguished from inorganic coatings.

The calculated values of $\delta_{l}$ are predominantly in the lower range of reported field measurements. This may indicate that the free parameter in our model, the critical diameter $D_{c}$ of the coating, should be increased, which would result in higher values of $\delta_{l}$. However, the field observations only provide us with a fairly broad gauge, but not with a reliable method to constrain the model. A more detailed tuning of the model will have to rely on suitable laboratory observations of coated black carbon aerosols with as complete a characterisation as possible of the physical properties and composition.

Assuming a particle size distribution with a fixed soot volume fraction, i.e. a fixed amount of coating per particle is a necessary simplification. Future studies could address the impact of a coating thickness distribution combined with a particle size distribution. Varying the coating thickness increases the effect of the different surface tensions of the coating materials. The impact of surface tension differences are reflected by changes in critical diameter $D_{c}$. This, in turn, will impact the particle shape, hence the extinction-to-backscatter ratio and depolarisation ratio.

\section{Funding}

F. Kanngießer acknowledges funding by the Swedish Research Council (Vetenskapsrådet) under contract 2016-03499. M. Kahnert acknowledges funding by the Swedish National Space Agency (Rymdstyrelsen) under contract 100/16.

\section{Acknowledgments}

The calculations were partly performed on resources at Chalmers Centre for Computational Science and Engineering (C3SE) provided by the Swedish National Infrastructure for Computing (SNIC). We are grateful to Dan Mackowski for providing his cluster-cluster aggregation algorithm. Alfons G. Hoekstra and Maxim A. Yurkin are acknowledged for making their ADDA code publicly available.

\section{Disclosures.}

The authors declare no conflicts of interest.

\section{References}

1. P. Chýlek, G. B. Lesins, G. Videen, J. G. D. Wong, R. G. Pinnick, D. Ngo, and J. D. Klett, "Black carbon and absorption of solar radiation by clouds," J. Geophys. Res. 101, 23365-23371 (1996).

2. T. C. Bond and R. W. Bergstrom, "Light absorption by carbonaceous particles: An investigative review," Aerosol Sci. Technol. 40, 27-67 (2006).

3. T. C. Bond, S. J. Doherty, D. W. Fahey, P. M. Forster, T. Berntsen, B. J. DeAngelo, M. G. Flanner, S. Ghan, B. Kärcher, D. Koch, S. Kinne, Y. Kondo, P. K. Quinn, M. C. Sarofim, M. G. Schultz, M. Schulz, C. Venkataraman, H. Zhang, S. Zhang, N. Bellouin, S. K. Guttikunda, P. K. Hopke, M. Z. Jacobson, J. W. Kaiser, Z. Klimont, U. Lohmann, J. P. Schwarz, D. Shindell, T. Storelvmo, S. G. Warren, and C. S. Zender, "Bounding the role of black carbon in the climate system: A scientific assessment," J. Geophys. Res. 118, 5380-5552 (2013).

4. S. C. Anenberg, K. Talgo, S. Arunachalam, P. Dolwick, C. Jang, and J. J. West, "Impacts of global, regional, and sectoral black carbon emission reductions on surface air quality and human mortality," Atmos. Chem. Phys. 11, $7253-7267$ (2011).

5. A. H. Omar, D. M. Winker, M. A. Vaughan, Y. Hu, C. R. Trepte, R. A. Ferrare, K.-P. Lee, C. A. Hostetler, C. Kittaka, R. R. Rogers, R. E. Kuehn, and Z. Liu, "The calipso automated aerosol classification and lidar ratio selection algorithm," J. Atmos. Ocean. Technol. 26, 1994-2014 (2009).

6. M.-H. Kim, A. H. Omar, J. L. Tackett, M. A. Vaughan, D. M. Winker, C. R. Trepte, Y. Hu, Z. Liu, L. R. Poole, M. C. Pitts, J. Kar, and B. E. Magill, "The calipso version 4 automated aerosol classification and lidar ratio selection algorithm,” Atmos. Meas. Tech. 11, 6107-6135 (2018). 
7. A. J. Illingworth, H. W. Barker, A. Beljaars, M. Ceccaldi, H. Chepfer, N. Clerbaux, J. Cole, J. Delanoë, C. Domenech, D. P. Donovan, S. Fukuda, M. Hirakata, R. J. Hogan, A. Huenerbein, P. Kollias, T. Kubota, T. Nakajima, T. Y. Nakajima, T. Nishizawa, Y. Ohno, H. Okamoto, R. Oki, K. Sato, M. Satoh, M. W. Shephard, A. Velázquez-Blázquez, U. Wandinger, T. Wehr, and G.-J. van Zadelhoff, "The earthcare satellite: The next step forward in global measurements of clouds, aerosols, precipitation, and radiation,” Bull. Amer. Meteor. Soc. 96, 1311-1332 (2015).

8. M. I. Mishchenko and J. W. Hovenier, "Depolarization of light backscattered by randomly oriented nonspherical particles," Opt. Lett. 20, 1356-1358 (1995).

9. M. I. Mishchenko and K. Sassen, "Depolarization of lidar returns by small ice crystals: An application to contrails," Geophys. Res. Lett. 25, 309-312 (1998).

10. M. Kahnert, "Modelling radiometric properties of inhomogeneous mineral dust particles: Applicability and limitations of effective medium theories," J. Quant. Spectrosc. Radiat. Transf. 152, 16-27 (2015).

11. M. I. Mishchenko, L. D. Travis, R. A. Kahn, and R. A. West, "Modeling phase functions for dustlike tropospheric aerosols using a shape mixture of randomly oriented polydisperse spheroids," J. Geophys. Res. 102, 16831-16847 (1997).

12. I. Veselovskii, O. Dubovik, A. Kolgotin, T. Lapyonok, P. Di Girolamo, D. Summa, D. N. Whiteman, M. Mishchenko, and D. Tanré, "Application of randomly oriented spheroids for retrieval of dust particle parameters from multiwavelength lidar measurements," J. Geophys. Res. 115 (2010).

13. R. Zhang, A. F. Khalizov, J. Pagels, D. Zhang, H. Xue, and P. H. McMurry, "Variability in morphology, hygroscopicity, and optical properties of soot aerosols during atmospheric processing," Proc. Natl. Acad. Sci. U.S.A. 105, 10291-10296 (2008).

14. K. Adachi and P. R. Buseck, "Internally mixed soot, sulfates, and organic matter in aerosol particles from mexico city," Atmos. Chem. Phys. 8, 6469-6481 (2008).

15. K. Adachi, S. H. Chung, and P. R. Buseck, "Shapes of soot aerosol particles and implications for their effects on climate," J. Geophys. Res. 115, n/a-n/a (2010).

16. A. Worringen, M. Ebert, T. Trautmann, S. Weinbruch, and G. Helas, "Optical properties of internally mixed ammonium sulfate and soot particles-a study of individual aerosol particles and ambient aerosol populations," Appl. Opt. 47, 3835-3845 (2008).

17. S. China, C. Mazzoleni, K. Gorkowski, A. C. Aiken, and M. K. Dubey, "Morphology and mixing state of individual freshly emitted wildfire carbonaceous particles," Nat. Commun. 4 (2013).

18. M. Kahnert, T. Nousiainen, and H. Lindqvist, "Models for integrated and differential scattering optical properties of encapsulated light absorbing carbon aggregates," Opt. Express 21, 7974-7993 (2013).

19. M. I. Mishchenko, J. M. Dlugach, and L. Liu, "Linear depolarization of lidar returns by aged smoke particles," Appl. Opt. 55 (2016).

20. M. Kahnert, "Optical properties of black carbon aerosols encapsulated in a shell of sulfate: comparison of the closed cell model with a coated aggregate model," Opt. Express 25, 24579-24593 (2017).

21. F. Kanngießer and M. Kahnert, "Calculation of optical properties of light-absorbing carbon with weakly absorbing coating: A model with tunable transition from film-coating to spherical-shell coating," J. Quant. Spectrosc. Radiat. Transf. 216, 17 - 36 (2018).

22. L. Liu and M. I. Mishchenko, "Scattering and radiative properties of morphologically complex carbonaceous aerosols: A systematic modeling study," Remote. Sens. 10 (2018).

23. H. Ishimoto, R. Kudo, and K. Adachi, "A shape model of internally mixed soot particles derived from artificial surface tension," Atmospheric Meas. Tech. 12, 107-118 (2019).

24. Z. Liu, N. Sugimoto, and T. Murayama, "Extinction-to-backscatter ratio of asian dust observed with high-spectralresolution lidar and raman lidar," Appl. Opt. 41, 2760-2767 (2002).

25. C. M. Sorensen, "Light scattering by fractal aggregates: A review," Aerosol Sci. Technol. 35, 648-687 (2001).

26. C. M. Sorensen and G. C. Roberts, "The prefactor of fractal aggregates," J. Colloid Interface Sci. 186, 447 - 452 (1997).

27. D. W. Mackowski, "A simplified model to predict the effects of aggregation on the absorption properties of soot particles,” J. Quant. Spectrosc. Radiat. Transf. 100, 237-249 (2006). VIII Conference on Electromagnetic and Light Scattering by Nonspherical Particles.

28. A. Brasil, T. Farias, and M. Carvalho, "A recipe for image characterization of fractal-like aggregates," J. Aerosol Sci. 30, 1379-1389 (1999).

29. J. Yon, A. Bescond, and F. Liu, “On the radiative properties of soot aggregates part 1: Necking and overlapping," J. Quant. Spectrosc. Radiat. Transf. 162 (2015).

30. C. Oh and C. Sorensen, "The effect of overlap between monomers on the determination of fractal cluster morphology," J. Colloid Interface Sci. 193, 17 - 25 (1997).

31. X. Pei, M. Hallquist, A. C. Eriksson, J. Pagels, N. M. Donahue, T. Mentel, B. Svenningsson, W. Brune, and R. K. Pathak, "Morphological transformation of soot: investigation of microphysical processes during the condensation of sulfuric acid and limonene ozonolysis product vapors," Atmos. Chem. Phys. 18, 9845-9860 (2018).

32. P. Liu, Y. Zhang, and S. T. Martin, "Complex refractive indices of thin films of secondary organic materials by spectroscopic ellipsometry from 220 to 1200 nm," Environ. Sci. Technol. 47, 13594-13601 (2013). PMID: 24191734.

33. M. Hess, P. Koepke, and I. Schult, "Optical properties of aerosols and clouds: The software package opac," Bull. Amer. Meteor. Soc. 79 (1998). 
34. H. Chang and T. T. Charalampopoulos, "Determination of the wavelength dependence of refractive indices of flame soot," Proc. R. Soc. Lond. 430, 577-591 (1990).

35. P. F. Liu, N. Abdelmalki, H.-M. Hung, Y. Wang, W. H. Brune, and S. T. Martin, "Ultraviolet and visible complex refractive indices of secondary organic material produced by photooxidation of the aromatic compounds toluene and m-xylene," Atmos. Chem. Phys. 15, 1435-1446 (2015).

36. U. Wandinger, Raman Lidar (Springer New York, 2005), pp. 241-271.

37. E. E. Eloranta, High Spectral Resolution Lidar (Springer New York, 2005), pp. 143-163.

38. S. P. Burton, J. W. Hair, M. Kahnert, R. A. Ferrare, C. A. Hostetler, A. L. Cook, D. B. Harper, T. A. Berkoff, S. T. Seaman, J. E. Collins, M. A. Fenn, and R. R. Rogers, "Observations of the spectral dependence of linear particle depolarization ratio of aerosols using nasa langley airborne high spectral resolution lidar," Atmos. Chem. Phys. 15, 13453-13473 (2015).

39. M. Haarig, A. Ansmann, H. Baars, C. Jimenez, I. Veselovskii, R. Engelmann, and D. Althausen, "Depolarization and lidar ratios at 355, 532, and $1064 \mathrm{~nm}$ and microphysical properties of aged tropospheric and stratospheric canadian wildfire smoke," Atmos. Chem. Phys. 2018, 11847-11861 (2018).

40. M. A. Yurkin and A. G. Hoekstra, "The discrete-dipole-approximation code adda: Capabilities and known limitations," J. Quant. Spectrosc. Radiat. Transf. 112 (2011).

41. M. Yurkin and A. Hoekstra, "The discrete dipole approximation: An overview and recent developments," J. Quant. Spectrosc. Radiat. Transf. 106, 558-589 (2007). IX Conference on Electromagnetic and Light Scattering by Non-Spherical Particles.

42. M. Kahnert, "Numerical solutions of the macroscopic maxwell equations for scattering by non-spherical particles: A tutorial review," J. Quant. Spectrosc. Radiat. Transf. 178, 22 - 37 (2016). Electromagnetic and light scattering by nonspherical particles XV: Celebrating 150 years of Maxwell's electromagnetics.

43. J. Gasteiger, M. Wiegner, S. Groß, V. Freudenthaler, C. Toledano, M. Tesche, and K. Kandler, "Modelling lidar-relevant optical properties of complex mineral dust aerosols," Tellus B 63, 725-741 (2011).

44. A. Ansmann, F. Wagner, D. Müller, D. Althausen, A. Herber, W. von Hoyningen-Huene, and U. Wandinger, "European pollution outbreaks during ace 2: Optical particle properties inferred from multiwavelength lidar and star-sun photometry," J. Geophys. Res. 107, AAC 8-1-AAC 8-14 (2002).

45. D. Müller, A. Ansmann, I. Mattis, M. Tesche, U. Wandinger, D. Althausen, and G. Pisani, "Aerosol-type-dependent lidar ratios observed with raman lidar," J. Geophys. Res. 112 (2007).

46. P. Ortiz-Amezcua, J. L. Guerrero-Rascado, M. J. Granados-Muñoz, J. A. Benavent-Oltra, C. Böckmann, S. Samaras, I. S. Stachlewska, Ł. Janicka, H. Baars, S. Bohlmann, and L. Alados-Arboledas, "Microphysical characterization of long-range transported biomass burning particles from north america at three earlinet stations," Atmos. Chem. Phys. 17, 5931-5946 (2017)

47. J. Preißler, F. Wagner, J. L. Guerrero-Rascado, and A. M. Silva, "Two years of free-tropospheric aerosol layers observed over portugal by lidar," J. Geophys. Res. 118, 3676-3686 (2013).

48. L. Janicka and I. S. Stachlewska, "Properties of biomass burning aerosol mixtures derived at fine temporal and spatial scales from raman lidar measurements: Part i optical properties," Atmos. Chem. Phys. Discuss. 2019, 1-46 (2019).

49. S. P. Burton, R. A. Ferrare, C. A. Hostetler, J. W. Hair, R. R. Rogers, M. D. Obland, C. F. Butler, A. L. Cook, D. B. Harper, and K. D. Froyd, "Aerosol classification using airborne high spectral resolution lidar measurements methodology and examples," Atmos. Meas. Tech. 5, 73-98 (2012).

50. Q. Hu, P. Goloub, I. Veselovskii, J.-A. Bravo-Aranda, I. E. Popovici, T. Podvin, M. Haeffelin, A. Lopatin, O. Dubovik, C. Pietras, X. Huang, B. Torres, and C. Chen, "Long-range-transported canadian smoke plumes in the lower stratosphere over northern france," Atmos. Chem. Phys. 19, 1173-1193 (2019).

51. J. Gasteiger and V. Freudenthaler, "Benefit of depolarization ratio at $\lambda=1064 \mathrm{~nm}$ for the retrieval of the aerosol microphysics from lidar measurements," Atmos. Meas. Tech. 7, 3773-3781 (2014).

52. T. W. Kirchstetter, T. Novakov, and P. V. Hobbs, "Evidence that the spectral dependence of light absorption by aerosols is affected by organic carbon," J. Geophys. Res. 109 (2004).

53. R. W. Bergstrom, P. Pilewskie, P. B. Russell, J. Redemann, T. C. Bond, P. K. Quinn, and B. Sierau, "Spectral absorption properties of atmospheric aerosols," Atmos. Chem. Phys. 7, 5937-5943 (2007).

54. P. B. Russell, R. W. Bergstrom, Y. Shinozuka, A. D. Clarke, P. F. DeCarlo, J. L. Jimenez, J. M. Livingston, J. Redemann, O. Dubovik, and A. Strawa, "Absorption angstrom exponent in aeronet and related data as an indicator of aerosol composition," Atmos. Chem. Phys. 10, 1155-1169 (2010).

55. J. S. Reid, T. F. Eck, S. Christopher, P. V. Hobbs, and B. Holben, "Use of the Ångstrom exponent to estimate the variability of optical and physical properties of aging smoke particles in brazil," J. Geophys. Res. 104, 27473-27489 (1999).

56. I. Veselovskii, P. Goloub, T. Podvin, V. Bovchaliuk, Y. Derimian, P. Augustin, M. Fourmentin, D. Tanre, M. Korenskiy, D. N. Whiteman, A. Diallo, T. Ndiaye, A. Kolgotin, and O. Dubovik, "Retrieval of optical and physical properties of african dust from multiwavelength raman lidar measurements during the shadow campaign in senegal," Atmos. Chem. Phys. 16, 7013-7028 (2016).

57. A. Ansmann, M. Riebesell, and C. Weitkamp, "Measurement of atmospheric aerosol extinction profiles with a raman lidar," Opt. Lett. 15, 746-748 (1990).

58. A. Ansmann, U. Wandinger, M. Riebesell, C. Weitkamp, and W. Michaelis, "Independent measurement of extinction and backscatter profiles in cirrus clouds by using a combined raman elastic-backscatter lidar,” Appl. Opt. 31, 
7113-7131 (1992).

59. V. Freudenthaler, M. Esselborn, M. Wiegner, B. Heese, M. Tesche, A. Ansmann, D. Müller, D. Althausen, M. Wirth, A. Fix, G. Ehret, P. Knippertz, C. Toledano, J. Gasteiger, M. Garhammer, and M. Seefeldner, "Depolarization ratio profiling at several wavelengths in pure saharan dust during samum 2006," Tellus B 61, 165-179 (2009).

60. J. W. Hair, C. A. Hostetler, A. L. Cook, D. B. Harper, R. A. Ferrare, T. L. Mack, W. Welch, L. R. Izquierdo, and F. E. Hovis, "Airborne high spectral resolution lidar for profiling aerosol optical properties," Appl. Opt. 47, 6734-6752 (2008).

61. L. Janicka, I. S. Stachlewska, I. Veselovskii, and H. Baars, "Temporal variations in optical and microphysical properties of mineral dust and biomass burning aerosol derived from daytime raman lidar observations over warsaw, poland," Atmos. Environ. 169, 162 - 174 (2017).

62. S. Groß, M. Tesche, V. Freudenthaler, C. Toledano, M. Wiegner, A. Ansmann, D. Althausen, and M. Seefeldner, "Characterization of saharan dust, marine aerosols and mixtures of biomass-burning aerosols and dust by means of multi-wavelength depolarization and raman lidar measurements during samum 2," Tellus B 63, 706-724 (2011).

63. S. N. Pereira, J. Preißler, J. L. Guerrero-Rascado, A. M. Silva, and F. Wagner, "Forest fire smoke layers observed in the free troposphere over portugal with a multiwavelength raman lidar: Optical and microphysical properties," Sci. World J. 2104, 421838 (2014).

64. H. Baars, A. Ansmann, D. Althausen, R. Engelmann, B. Heese, D. Müller, P. Artaxo, M. Paixao, T. Pauliquevis, and R. Souza, "Aerosol profiling with lidar in the amazon basin during the wet and dry season," J. Geophys. Res. 117, n/a-n/a (2012).

65. D. Müller, I. Mattis, U. Wandinger, A. Ansmann, D. Althausen, and A. Stohl, "Raman lidar observations of aged siberian and canadian forest fire smoke in the free troposphere over germany in 2003: Microphysical particle characterization," J. Geophys. Res. 110, n/a-n/a (2005). D17201.

66. D. Nicolae, A. Nemuc, D. Müller, C. Talianu, J. Vasilescu, L. Belegante, and A. Kolgotin, "Characterization of fresh and aged biomass burning events using multiwavelength raman lidar and mass spectrometry," J. Geophys. Res. 118, 2956-2965 (2013).

67. M. Tesche, S. Gross, A. Ansmann, D. Müller, D. Althausen, V. Freudenthaler, and M. Esselborn, "Profiling of saharan dust and biomass-burning smoke with multiwavelength polarization raman lidar at cape verde," Tellus B 63 , 649-676 (2011).

68. A. Ansmann, H. Baars, M. Tesche, D. Müller, D. Althausen, R. Engelmann, T. Pauliquevis, and P. Artaxo, "Dust and smoke transport from africa to south america: Lidar profiling over cape verde and the amazon rainforest," Geophys. Res. Lett. 36, n/a-n/a (2009). L11802.

69. E. Giannakaki, P. G. van Zyl, D. Müller, D. Balis, and M. Komppula, "Optical and microphysical characterization of aerosol layers over south africa by means of multi-wavelength depolarization and raman lidar measurements," Atmos. Chem. Phys. 16, 8109-8123 (2016).

70. Y. M. Noh, D. Müller, D. H. Shin, H. Lee, J. S. Jung, K. H. Lee, M. Cribb, Z. Li, and Y. J. Kim, "Optical and microphysical properties of severe haze and smoke aerosol measured by integrated remote sensing techniques in gwangju, korea," Atmos. Environ. 43, 879 - 888 (2009).

71. T. Murayama, D. Müller, K. Wada, A. Shimizu, M. Sekiguchi, and T. Tsukamoto, "Characterization of asian dust and siberian smoke with multi-wavelength raman lidar over tokyo, japan in spring 2003," Geophys. Res. Lett. 31, n/a-n/a (2004). L23103.

72. L. Alados-Arboledas, D. Müller, J. L. Guerrero-Rascado, F. Navas-Guzmán, D. Pérez-Ramírez, and F. J. Olmo, "Optical and microphysical properties of fresh biomass burning aerosol retrieved by raman lidar, and star-and sun-photometry," Geophys. Res. Lett. 38 (2011). 